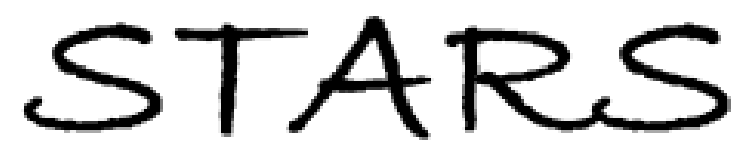

University of Central Florida

STARS

$1-1-1999$

\title{
Processing and characterization of nanometer sized copper sulfide particles
}

\author{
S. Seal \\ University of Central Florida \\ L. Bracho \\ University of Central Florida \\ S. Shukla \\ University of Central Florida \\ J. Morgiel
}

Find similar works at: https://stars.library.ucf.edu/facultybib1990

University of Central Florida Libraries http://library.ucf.edu

This Article; Proceedings Paper is brought to you for free and open access by the Faculty Bibliography at STARS. It has been accepted for inclusion in Faculty Bibliography 1990s by an authorized administrator of STARS. For more information, please contact STARS@ucf.edu.

\section{Recommended Citation}

Seal, S.; Bracho, L.; Shukla, S.; and Morgiel, J., "Processing and characterization of nanometer sized copper sulfide particles" (1999). Faculty Bibliography 1990s. 2838.

https://stars.library.ucf.edu/facultybib1990/2838

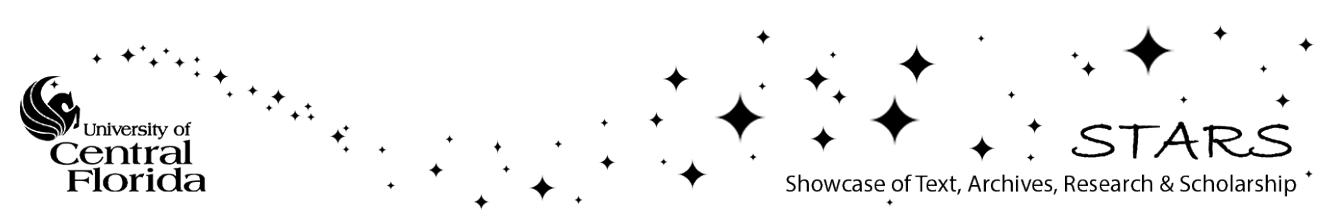




\section{Processing and characterization of nanometer sized copper sulfide particles}

S. Seal, L. Bracho, S. Shukla, and J. Morgiel

Citation: Journal of Vacuum Science \& Technology A 17, 2950 (1999); doi: 10.1116/1.581966

View online: https://doi.org/10.1116/1.581966

View Table of Contents: https://avs.scitation.org/toc/jva/17/5

Published by the American Vacuum Society

\section{ARTICLES YOU MAY BE INTERESTED IN}

Nanometer-scale switches using copper sulfide

Applied Physics Letters 82, 3032 (2003); https://doi.org/10.1063/1.1572964

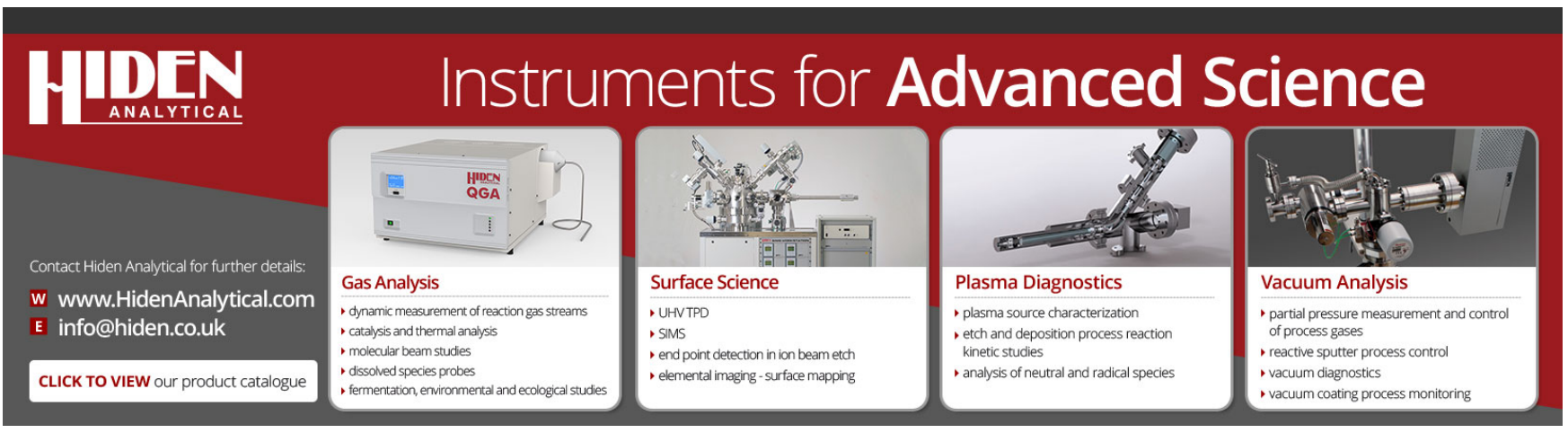




\title{
Processing and characterization of nanometer sized copper sulfide particles
}

\author{
S. Seal, ${ }^{\text {a) }}$ L. Bracho, and S. Shukla \\ Advanced Materials Processing Analysis Center (AMPAC), and Mechanical, \\ Materials \& Aerospace Engineering (MMAE), University of Central Florida, Orlando, Florida 32816 \\ J. Morgiel \\ Institute of Metallurgy and Materials Science, Polish Academy of Sciences, 25 Reymonta Street, \\ 30-059 Krakow, Poland
}

(Received 2 November 1998; accepted 21 June 1999)

\begin{abstract}
Nanomaterials have attracted considerable attention in modern-day technology. In this article, sulfide nanoparticles of industrial interest are formed by the sol-gel process using metal chloride precursors dissolved in a mixture of silica gel and organic cellulose network followed by a chemical reaction with hydrogen sulfide gas. Particles are then heated in a vacuum oven. While scanning and transmission electron microscopy are used to study their morphology and structure in the nanometer scale, $\mathrm{x}$-ray photoelectron spectroscopy is employed to understand the bonding chemistry and the stoichiometry of the sulfide particles as a function of $\mathrm{H}_{2} \mathrm{~S}$ exposure and heat treatment. The results from this study are expected to show promising applications and production of other oxides, sulfides and their compounds using sol-gel synthesis are indicated. (c) 1999 American Vacuum Society. [S0734-2101(99)10005-8]
\end{abstract}

\section{INTRODUCTION}

During the past decade, nanomaterials have attracted considerable interest in technological revolution. The physicochemical as well as magnetic and optical properties of nanomaterials are very different from their bulk because the particle size diameters are less than the Bohr exciton radius. ${ }^{1}$ Nanoparticles hold a promising future in electronics; as precursors for building components of the chips or for development of new photocells and sensors, or for generating very small active elements in magnetic recording. ${ }^{2}$ This has promoted the development of various processing techniques, such as the sol-gel process, ${ }^{3}$ chemical vapor deposition, ${ }^{4}$ and electrochemical and chemical processing with organometallic precursors. ${ }^{5}$ Besides processing, an intensive characterization of nanoparticles using scanning electron microscope (SEM), transmission electron microscope (TEM, for determining the particle size), X-ray diffraction (XRD, for determining the crystalline nature of the particles), and X-ray photoelectron spectroscopy (XPS, for determining the chemical states, stoichiometry of the films and other chemical species in the matrix) is needed to understand the material behavior in nanophase.

Due to high surface reactivity, synthesizing nanoparticles, however, pose real challenges because of their agglomeration. Sol-gel synthesis offers a great degree of control of the atomic composition and structure at the molecular level, which is unachievable with traditional sintering or precipitation methods. Since the chemistry and microstructure of the solid determine its properties, this technology can be used to design materials with specified mechanical, optical, electronic, and physicochemical properties. ${ }^{6}$ Nanosized particles,

${ }^{a)}$ Electronic mail: sseal@pegasus.cc.ucf.edu such as $\mathrm{CdS}, \mathrm{PbS}, \mathrm{ZnS}, \mathrm{Fe}_{2} \mathrm{O}_{3}$, produced by the sol-gel technique have been reported. ${ }^{7-9}$

The present article reports the processing and characterization of $\mathrm{CuS}$ nanoparticles dispersed in hydroxypropyl cellulose (HPC)-silica films with the gas diffusion method. CuS is a potential material for lubricant and solar cells based on cadmium sulfides. Metal precursors are dissolved in the matrices and converted to nanoparticles by chemical reaction. It is to be noted in our experiments that HPC, an organic polymer with $\mathrm{OH}$ groups, facilitates the formation of a homogeneous organic-polymer silica film for fine dispersion of a $\mathrm{Cu}$-metal precursor for $\mathrm{CuS}$ production.

\section{EXPERIMENT}

\section{A. Materials processing}

$\mathrm{HPC}, \mathrm{CuCl}_{2}, \mathrm{AlCl}_{3}, \mathrm{HCl}$, TEOS (tetraethyl orthosilicate) were purchased from Aldrich Chemicals, USA. The proce-

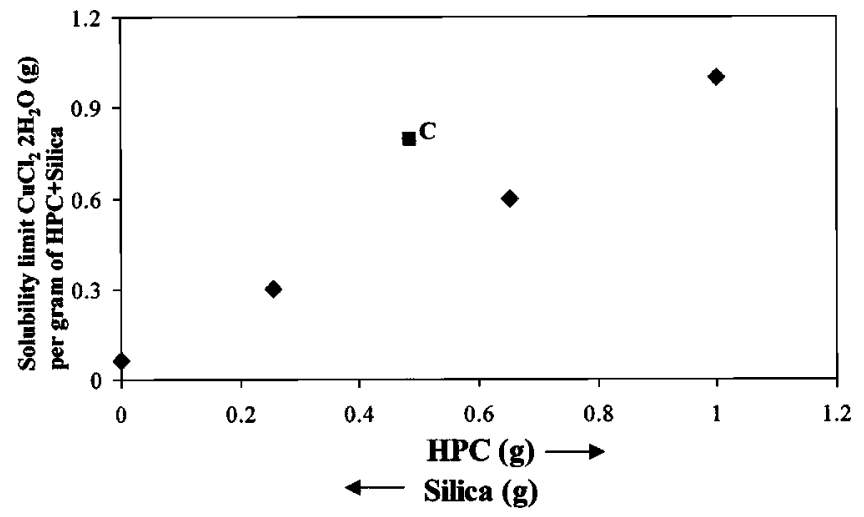

FIG. 1. Calculated solubility limit of copper chloride as a function of HPC and silica content. The point $\mathrm{C}$ is our chosen composition (includes the $\mathrm{AlCl}_{3}$ addition) for nanoparticle processing. 


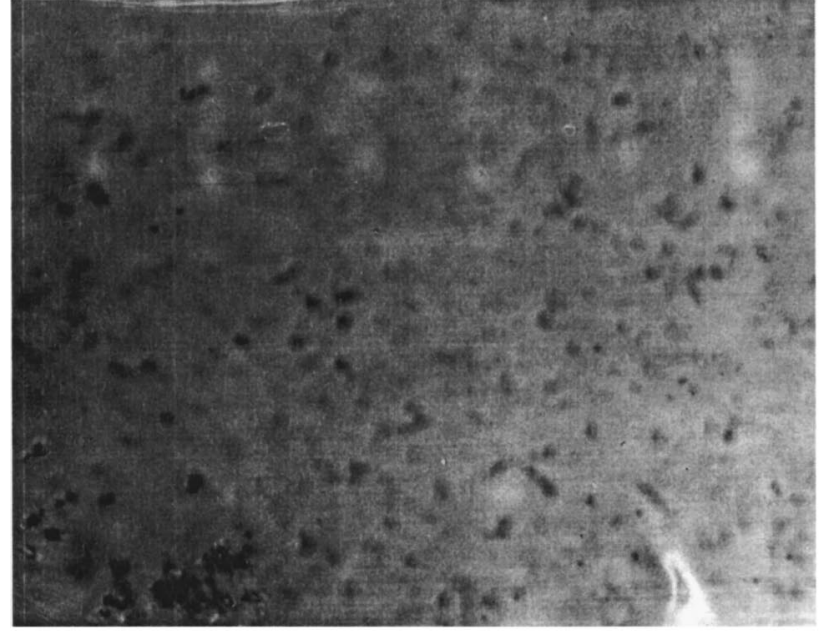

(a)

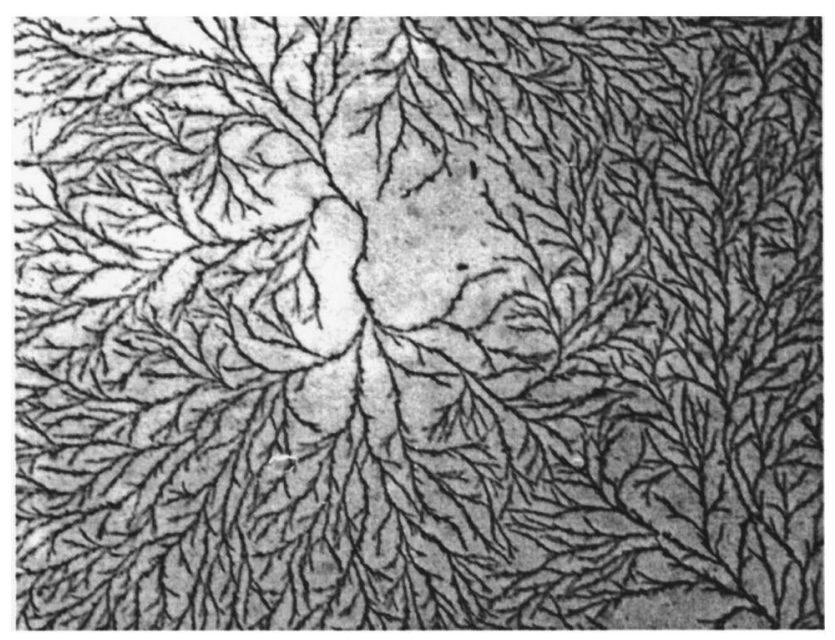

(b)

FIG. 2. Optical micrographs of CuS particles, (a) freshly prepared and (b) with time (network formation): Mag: 1000X

dure for preparation of HPC-silica films containing $\mathrm{CuS}$ nanoparticles is described below. A dipping solution for preparation of the $\mathrm{CuS}$ precursor films was prepared by dissolving $\mathrm{CuCl}_{2}, \mathrm{AlCl}_{3}$, and silica sol in $100 \mathrm{ml}$ of methanol containing $0.5 \mathrm{gm}$ of HPC.

The silica sol was prepared from hydrolysis of TEOS by dissolving $10 \mathrm{~g}$ of TEOS in a mixture of water, methanol (anhydrous), and hydrochloric acid (35\%). A homogeneous mixture of silica sol solution was prepared after stirring the mixture for half an hour. Excessive stirring leads to hardening of the silica sol and makes it unusable.

Chosen metal precursor films were formed on glass plates by the dip drying method at room temperature. The plates (roughened for better adhesion) were dipped (once) in the solution for 1-2 $\min$ and were dried for 3-4 $\min (\mathrm{s})$ before $\mathrm{H}_{2} \mathrm{~S}$ exposure. The nanophase $\mathrm{CuS}$ dispersed films were obtained by exposing the precursor films to $\mathrm{H}_{2} \mathrm{~S}$ for $2-5 \mathrm{~s}$ followed by heating in a vacuum furnace $\left(1 \times 10^{-4}\right.$ Torr $)$ at $150-180^{\circ} \mathrm{C}$ for $1 \mathrm{~h}$. The conversion of $\mathrm{CuCl}_{2}$ to $\mathrm{CuS}$ is

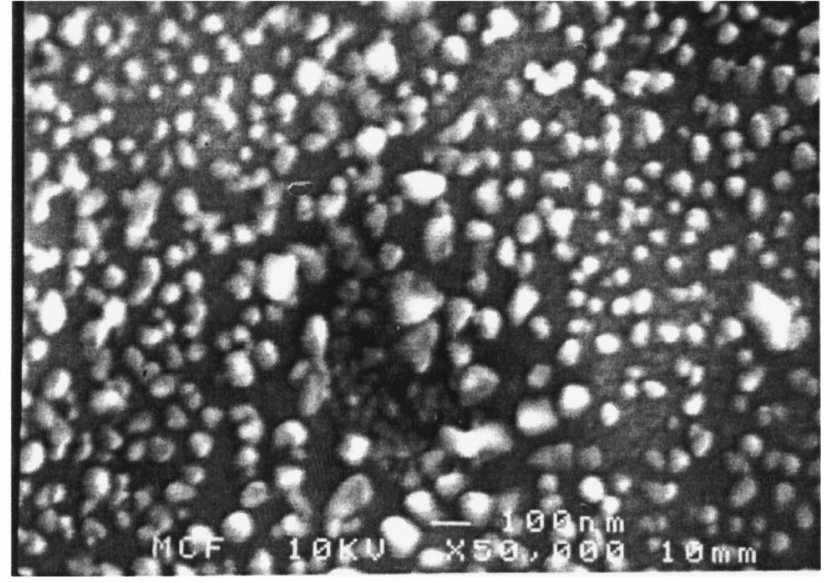

(a)

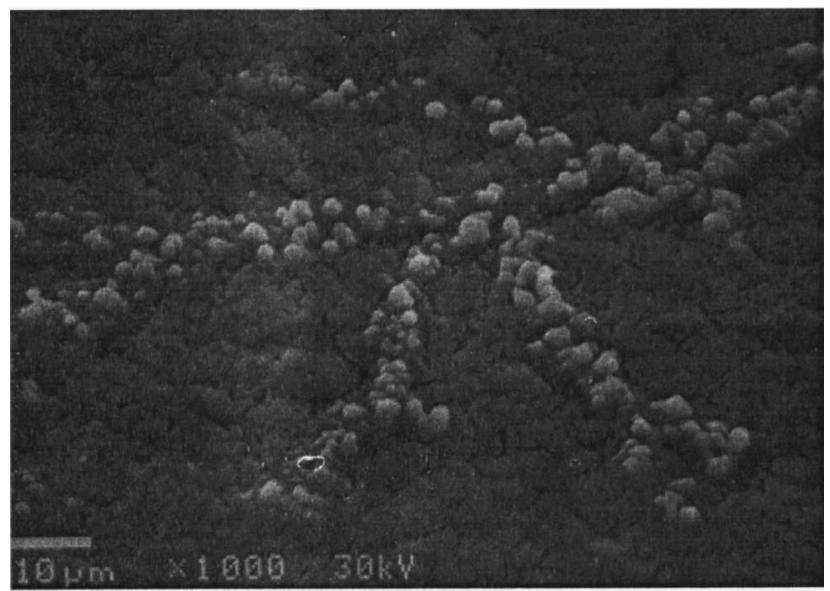

(b)

FIG. 3. SEM micrographs of CuS particles, (a) freshly prepared (nanometer sized) and (b) with time (network formation, particle growth and cluster).

indicated by a change in film color from light yellowish to blue during $\mathrm{H}_{2} \mathrm{~S}$ exposure.

\section{B. Particle morphology}

The particle size distribution was studied using an optical microscope and JEOL scanning electron microscope (SEM). The nanometer size sulfide particles were further characterized by transmission electron microscope Philips CM200FEG. The sample was ion milled in argon from one side of the glass plate at $4 \mathrm{kV}$.

\section{Surface chemical characterization}

The nanoparticle sulfide films produced on glass plates were characterized by a 5400 PHI ESCA (XPS) spectrometer having a base pressure of $10^{-10}$ Torr using $\mathrm{Al} K \alpha \mathrm{X}$ radiation $(1486 \mathrm{eV}$, linewidth $0.7 \mathrm{eV})$ with a power of $350 \mathrm{~W}$. Survey and individual high-resolution spectra were recorded with a pass energy of 44 and $17 \mathrm{eV}$ to achieve the maximum instrument resolution. The binding energy of the gold $\left(4 f_{7 / 2}\right)$ at $84 \pm 0.2 \mathrm{eV}$ was used to calibrate the binding energy scale of the spectrometer. Any charging shifts produced by the 


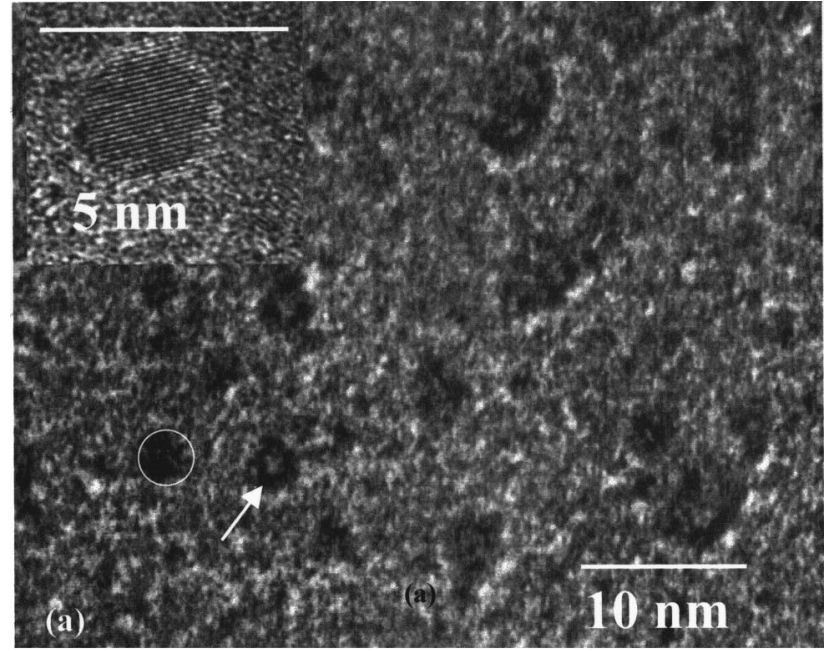

(a)

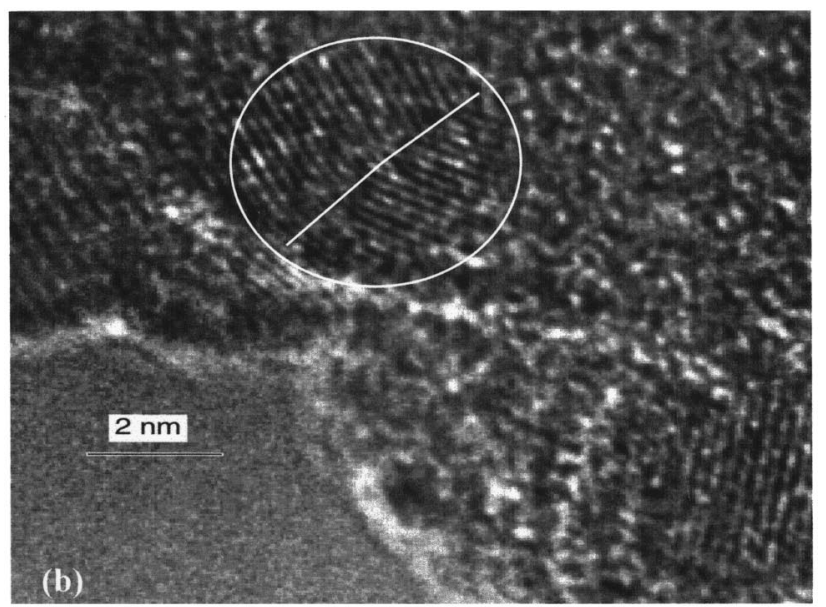

(b)

FIG. 4. TEM micrographs of $\mathrm{CuS}$ dispersed particles with $\mathrm{CuCl}_{2} \cdot 2 \mathrm{H}_{2} \mathrm{O} / \mathrm{HPC} /$ silica sol/ $/ \mathrm{AlCl}_{3}$, (a) uniformly distributed nanoparticles and (b) twining of $\mathrm{CuS}$ particle. samples were removed by using a binding energy scale referenced to $\mathrm{C}(1 s)$ binding energy of the hydrocarbon part of the adventitious carbon line at $284.6 \mathrm{eV} .{ }^{10}$ Nonlinear backgrounds were removed from the spectra using a method described by Sherwood. ${ }^{11}$ Nonlinear least-squares curve fitting was performed using a Gaussian/Lorentzian peak shape, ${ }^{11,12}$ after background removal using a method described in the literature. ${ }^{11}$ The peak heights and areas under the peaks have been used to measure the relative atomic concentrations.

\section{RESULTS AND DISCUSSIONS}

\section{A. Role of hydroxypropyl cellulose}

Particle size distribution is greatly affected by the inhomogeneous distribution of $\mathrm{Cu}^{+2}$ ions in $\mathrm{CuCl}_{2}$ containing matrix. HPC, a cellulose derivative, is one of the effective polymeric matrix for uniform distribution of metal precursors in the soluble matrix. Since $\mathrm{CuS}$ is produced by the $\mathrm{H}_{2} \mathrm{~S}$ gas diffusion, the diffusion of $\mathrm{Cu}^{+2}$ ions controls the particle growth. The polymeric sol-gel network is believed to suppress the $\mathrm{CuS}$ particle growth. The diffusion of $\mathrm{H}_{2} \mathrm{~S}$ gas into the matrix is responsible for copper sulfide reaction only. Moreover, HPC forms a molecular hybrid with silica via hydrogen bonds through its hydroxyl and ether groups. ${ }^{13}$ This allows HPC to act as a compatibilizer for uniform dispersion of $\mathrm{CuCl}_{2}$ in the silica matrix to a molecular level for producing nanometer sized particles. The XPS Si $(2 p)$ binding energy in silica gel is found to be $102.7 \mathrm{eV}$ (less than that of Si in silica $\sim 103.2 \mathrm{eV}$ ), indicating an enhanced covalency in the $\operatorname{Si}(2 p)$ character in the polymeric network.

\section{B. Effect of metal precursor solubility}

The calculated solubility of metal precursor $\left(\mathrm{CuCl}_{2}\right)$ in the HPC containing polymeric matrix is dependent on the silica and $\mathrm{HPC}$ content (see Fig. 1). $\mathrm{CuCl}_{2}$ crystals precipi-

TABLE I. Selected XPS core-level binding energies $( \pm 0.1 \mathrm{eV})$ of $\mathrm{CuS}$ nanoparticles processed via metal precursor and gas diffusion method. Reference binding energy $\mathrm{C}(1 s)=284.6 \mathrm{eV}$.

\begin{tabular}{lccccc}
\hline \hline & & & $\mathrm{S}(2 p)_{3 / 2} /$ & $\mathrm{Cl}(2 p)_{3 / 2} /$ & \\
& $\mathrm{C}(1 s)$ & $\mathrm{Cu}(2 p)_{3 / 2}$ & $(2 p)_{1 / 2}$ & $(2 p)_{1 / 2}$ & $\mathrm{Si}(2 p)$ \\
\hline No $_{2} \mathrm{~S} /$ & $\mathrm{C}-\mathrm{H}(\mathrm{L})$ & 933.6 & $\ldots$ & $199.9 / 202.2$ & 103.2 \\
no heat & $\mathrm{C}-\mathrm{O}-\mathrm{C}(\mathrm{L})$ & $\mathrm{CuO}$ & & $\mathrm{CuCl}_{2}$ & $\mathrm{SiO}_{2}(\mathrm{~L})$ \\
& $\mathrm{C}-\mathrm{OH}(\mathrm{L})$ & 934.9 & & $198.4 / 200.4$ & $102.5(\mathrm{~S})$ \\
& $\mathrm{C}=\mathrm{O}(\mathrm{S})$ & $\mathrm{CuCl}_{2}$ & & $\mathrm{AlCl}_{3}$ & \\
FWHM & & $(2.6 \mathrm{eV})$ & & $(3.4 \mathrm{eV})$ & $(2.5 \mathrm{eV})$ \\
$\mathrm{H}_{2} \mathrm{~S} /$ no & $\mathrm{C}-\mathrm{H}(\mathrm{L})$ & 931.6 & $161.5 / 162.7$ & $198.3 / 200.4$ & 102.5 \\
heat & $\mathrm{C}-\mathrm{O}-\mathrm{C}(\mathrm{L})$ & $\mathrm{CuS}$ & $\mathrm{CuS}$ & $\mathrm{AlCl}_{3}(\mathrm{~L})$ & \\
& $\mathrm{C}-\mathrm{OH}(\mathrm{M})$ & 932.5 & & & \\
& & $\mathrm{CuCl}(?)$ & $(2.9 \mathrm{eV})$ & $(2.9 \mathrm{eV})$ & $(1.9 \mathrm{eV})$ \\
FWHM & $(2.3 \mathrm{eV})$ & & & \\
$\mathrm{H}_{2} \mathrm{~S} /$ heat & $\mathrm{C}-\mathrm{H}$ & 931.6 & $161.6 / 162.8$ & $198.3 / 200.4$ & 102.6 \\
& $\mathrm{C}-\mathrm{O}-\mathrm{C}(\mathrm{M})$ & $\mathrm{CuS}$ & $\mathrm{CuS}$ & $\mathrm{AlCl}_{3}(\mathrm{~L})$ & \\
FWHM & $\mathrm{C}-\mathrm{OH}(\mathrm{S})$ & $(1.9 \mathrm{eV})$ & $(3.0 \mathrm{eV})$ & $(2.8 \mathrm{eV})$ & $(1.8 \mathrm{eV})$ \\
\hline \hline
\end{tabular}

${ }^{a}$ Note: () total full width half maximum, $\mathrm{L}=$ large, $\mathrm{M}=$ medium, $\mathrm{S}=$ small (XPS peak intensity). 

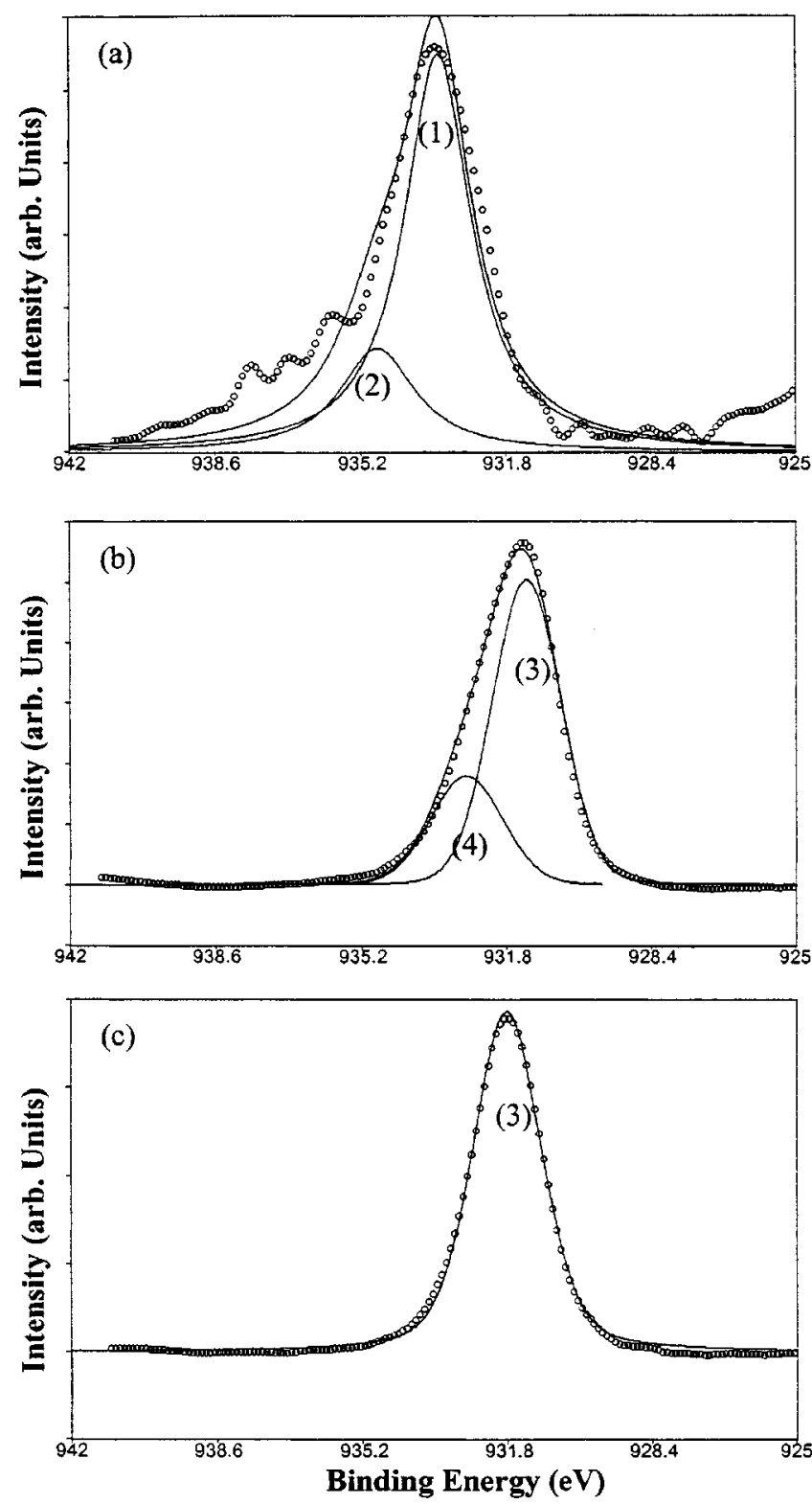

FIG. 5. XPS deconvoluted $\mathrm{Cu}\left(2 p_{3 / 2}\right)$ spectra for $\mathrm{CuCl}_{2} \cdot 2 \mathrm{H}_{2} \mathrm{O}$ / $\mathrm{HPC} /$ silica sol/ $/ \mathrm{AlCl}_{3}$ (a) film: no $\mathrm{H}_{2} \mathrm{~S}$, no heat (b) film: $\mathrm{H}_{2} \mathrm{~S}$, no heat (c) film: $\mathrm{H}_{2} \mathrm{~S}$, no heat. Suggested peak identification: (1) $\mathrm{CuO}$, (2) $\mathrm{CuCl}_{2}$, (3) $\mathrm{CuS},(4) \mathrm{CuCl}(?)$.

tated in the film after reaching its solubility limit as observed by a polarized microscope. With increase in HPC (and decrease in silica), the solubility limit of $\mathrm{CuCl}_{2} \cdot 2 \mathrm{H}_{2} \mathrm{O}$ increases because the $\mathrm{OH}$ groups in HPC provides an electron source for dissolution. Addition of $\mathrm{AlCl}_{3}$ in $\mathrm{HPC}$ and silica also increases the solubility of $\mathrm{CuCl}_{2}$ (shown in Fig. 1) due to its ionic nature and this is easily dissociated in the solution providing a high $\mathrm{CuCl}_{2}$ concentration in the homogeneous precursor film. The optimal $\mathrm{HPC}$, silica and $\mathrm{AlCl}_{3}$ composition (from Fig. 1: point $\mathrm{C}$ ) is chosen for producing $\mathrm{CuS}$ particles from its metal precursors.

\section{Particle size characterization}

$\mathrm{CuS}$ particles produced by the $\mathrm{H}_{2} \mathrm{~S}$ gas diffusion method are observed by optical, scanning electron and transmission

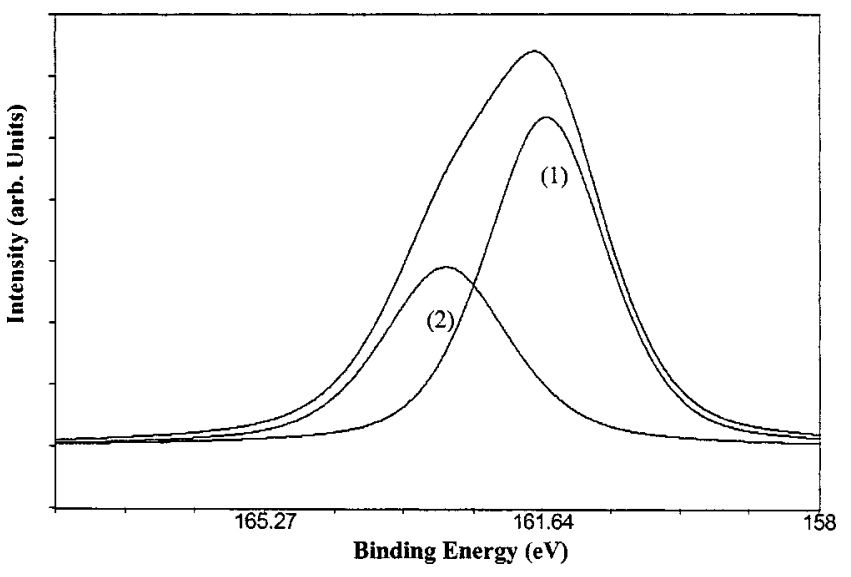

FIG. 6. XPS deconvoluted S $(2 p)$ spectrum for heated $\mathrm{CuS}$ nanoparticles. Suggested peak identification: CuS (1) S $2 p_{3 / 2}$, (2) S $2 p_{1 / 2}$.

electron microscope. Figures 2(a) and 2(b) are the optical micrographs of $\mathrm{CuS}$ particles. With time (no heating), the particles are found to form a chain of network as shown in Fig. 2(b) and this is also indicated by a particle growth [observed in SEM micrograph, Fig. 3(b)]. This network is believed to increase the conductivity of these sulfide films and this can be a potential use in the solar cell applications reported in the literature. ${ }^{14}$ The nature of the branching is identified as "fractals." These fractals follow a diffusion limited colloid aggregation (in three dimensions, $d_{f}=2.45$ ) and the condensation reaction is identified as a monomer-cluster interaction as also predicted by Witten and Sander model. ${ }^{15}$ Monomer cluster growth requires a continuous source of monomers which for either chemical or physical reasons, condense preferentially with clusters rather than with each other. It is believed that substantial concentrations of monomers are available from the TEOS derived silicates ${ }^{16}$ used in this research.

The SEM micrograph in Fig. 3(a) shows relatively spherical sized particles in the nanometer range. The particles precipitated by $\mathrm{H}_{2} \mathrm{~S}$ gas exposure were characterized with a Philips TEM. The particle size, distribution, and its structure are illustrated in Figs. 4(a) and 4(b). It is clear from the TEM micrographs that the particles are very spherical in nature and in the range of 2-7 $\mathrm{nm}$. Electron beam diffraction pattern showed the hexagonal symmetry of the $\mathrm{CuS}$ particles with a high degree of crystallinity. The isolated $\mathrm{CuS}$ particles, as viewed in the TEM, Fig. 4(a), is another indication of the homogeneous distribution of metal precursor in the polymeric matrix. It is to be noted that the particle sizes are in the range of 50-120 nm. Figure 4(b) shows a highresolution $\mathrm{CuS}$ (confirmed by EDS) particle with twins. Twins are a characteristic feature of this hep structure during early stages of nucleation. ${ }^{17}$

\section{Surface chemical studies}

Besides morphological characterization, it is imperative to facilitate the identification of $\mathrm{CuS}$ formation from the reaction between $\mathrm{CuCl}_{2}$ and $\mathrm{H}_{2} \mathrm{~S}\left(\mathrm{CuCl}_{2}+\mathrm{H}_{2} \mathrm{~S}=\mathrm{CuS}+2 \mathrm{HCl}\right)$. The XPS binding energies and full width at half maximum 
TABLE II. (a) Surface atomic concentrations (calculated from XPS survey spectra) of key matrix elements of $\mathrm{CuS}$ nanoparticles as a function of $\mathrm{H}_{2} \mathrm{~S}$ exposure and heat treatment. (b) Calculated XPS binding energies, Auger energies and the Auger parameter $(\mathrm{Al} K \alpha$ radiation, in $\mathrm{eV}$ ) in selected $\mathrm{Cu}$ compounds including $\mathrm{CuS}$ nanoparticles.

\begin{tabular}{|c|c|c|c|c|c|c|c|c|}
\hline (a) & $\mathrm{Cu}$ & $\mathrm{O}$ & $\mathrm{Cl}$ & S & $\mathrm{Si}$ & $\begin{array}{l}\text { Total } \\
\mathrm{Cu} / \mathrm{Cl}\end{array}$ & $\begin{array}{l}\text { Total } \\
\mathrm{Cu} / \mathrm{S}\end{array}$ & $\begin{array}{c}\text { Band } \\
\text { gap }(e V)\end{array}$ \\
\hline $\begin{array}{l}\text { No } \mathrm{H}_{2} \mathrm{~S} \\
\text { No heat }\end{array}$ & 1.42 & 76 & 0.71 & 0 & 22 & 2 & $\cdots$ & 2.95 \\
\hline $\begin{array}{l}\mathrm{H}_{2} \mathrm{~S} \\
\text { No heat }\end{array}$ & 4.60 & 93 & 0.74 & 0.53 & 1.80 & 6.21 & 8.7 & 1.6 \\
\hline $\begin{array}{l}\mathrm{H}_{2} \mathrm{~S} \\
\text { Heat }\end{array}$ & 17.0 & 79 & 0.50 & 1.80 & 0.89 & 31.4 & 9.8 & 0.9 \\
\hline & \multicolumn{2}{|c|}{$\begin{array}{l}\text { Binding } \\
\text { energy } \\
E_{B}(\mathrm{PE})\end{array}$} & \multicolumn{2}{|c|}{$\begin{array}{l}\text { Kinetic } \\
\text { energy } \\
E(\mathrm{PE})\end{array}$} & $\begin{array}{l}\text { Auger } \\
\text { energy } \\
E(\mathrm{~A})^{\alpha}\end{array}$ & \multicolumn{3}{|c|}{$\begin{array}{c}\text { Auger } \\
\text { parameter } \\
E(\mathrm{~A})-E(\mathrm{PE})\end{array}$} \\
\hline (b) & \multicolumn{4}{|c|}{$2 p_{3 / 2}$} & \multicolumn{3}{|c|}{$L_{3} M_{45} M_{45}$} & $-\Delta \alpha$ \\
\hline $\mathrm{CuO}\left(\mathrm{C}^{*}\right)$ & & & & & 918.1 & & 365.1 & \\
\hline $\mathrm{Cu}^{19}$ & & & & & 918.8 & & 364.6 & 0.5 \\
\hline $\mathrm{Cu}_{2} \mathrm{~S}^{19}$ & & & & & 917.6 & & 363.3 & 1.8 \\
\hline $\mathrm{CuS}(\mathrm{C})$ & & & & & 917.0 & & 362.0 & 3.1 \\
\hline
\end{tabular}

Note: $\mathrm{C} —$ calculated for $\mathrm{CuS}$ particles, heat treated, $\mathrm{PE}=$ photoelectron, $\left(\mathrm{C}^{*}\right)-$ calculated for $\mathrm{CuO}$ model compound.

(FWHM) of core levels of $\mathrm{Cu}$ and $\mathrm{S}$ in $\mathrm{CuS}$ are listed in Table I (along with $\mathrm{C}, \mathrm{Cl}$, and $\mathrm{Si}$ binding energies present in the matrix) as a function of $\mathrm{H}_{2} \mathrm{~S}$ exposure and heat treatment. The C $(1 s)$ spectra for all the samples [numbered as: (1) no $\mathrm{H}_{2} \mathrm{~S}$, no heat (FWHM $4.5 \mathrm{eV}$ ), (2) $\mathrm{H}_{2} \mathrm{~S}$, no heat (FWHM 3.7 $\mathrm{eV}$ ), and (3) $\mathrm{H}_{2} \mathrm{~S}$, heat (FWHM $3.6 \mathrm{eV}$ )] listed in Table I exhibit a broad peak consisting of multiple $\mathrm{C}-\mathrm{H}, \mathrm{C}-\mathrm{OH}$ (from organic polymer), $\mathrm{C}-\mathrm{O}-\mathrm{C}$ (from $\mathrm{HPC}$ ) and $\mathrm{C}=\mathrm{O}$ (surface oxidation) species. It is to be noted that the sample exposed to $\mathrm{H}_{2} \mathrm{~S}$ gas, followed by heat treatment, shows a decrease in both $\mathrm{C}-\mathrm{OH}$ and $\mathrm{C}-\mathrm{O}-\mathrm{C}$ content, an indication of the removal of organic sol-gel products during heating.

As expected, the binding energy of the $\mathrm{Cu}(2 p)_{3 / 2}$ line (FWHM $2.6 \mathrm{eV}$ ) in a non- $\mathrm{H}_{2} \mathrm{~S}$ exposed sample indicates the presence of both $\mathrm{CuO}(933.6 \mathrm{eV})$ and $\mathrm{CuCl}_{2}$ (934.9), Fig. 5(a). The corresponding $\mathrm{Cl}(2 p)$ at $199.9 \mathrm{eV}$ represents the $\mathrm{Cl}^{-}$in $\mathrm{CuCl}_{2}$. An additional peak at a lower binding energy $\sim 198.5 \mathrm{eV}$ indicates the presence of $\mathrm{AlCl}_{3}$ [corresponding $\mathrm{Al}(2 p)$ at $74.9 \mathrm{eV}]$ in the matrix. The $\mathrm{Al}(2 p)$ peak structure at 73.8 is that of $\mathrm{Al}_{2} \mathrm{O}_{3}$ and the polymeric network is probably the mixture of alumina and silica $[\mathrm{Si}(2 p) \sim 102.5 \mathrm{eV}]$ that is responsible for preventing the particle growth. The reduction in the $\operatorname{Si}(2 p)$ binding energy is due to the insertion of a more ionic $\mathrm{Al}-\mathrm{O}$ bond thus making the $\mathrm{Si}-\mathrm{O}$ bond more covalent. $^{18}$

After exposing the precursor film to $\mathrm{H}_{2} \mathrm{~S}$ (sample 2: $\mathrm{H}_{2} \mathrm{~S}$, no heat), the $\mathrm{Cu}(2 p)_{3 / 2}$ binding energy at $931.6 \mathrm{eV}$ (FWHM $2.3 \mathrm{eV}$ ) represents the presence of a divalent $\mathrm{Cu}$ in $\mathrm{CuS}$ and is consistent with the existing literature. ${ }^{14}$ The corresponding $\mathrm{S}\left(2 p_{3 / 2}\right)$ line at $161.5 \mathrm{eV}$ is an indicative of $\mathrm{CuS}$. An additional small peak at $932.5 \mathrm{eV}$ represents a possible presence of $\mathrm{CuCl}$ in the matrix, although its existence is not quite clear. The main $\mathrm{Cl}(2 p)$ peak at $198.3 \mathrm{eV}$ is mostly due to $\mathrm{AlCl}_{3}$. When the sample (No. 3) is heated to $150{ }^{\circ} \mathrm{C}$, the binding energy values of $\mathrm{Cu}(2 p)$ and $\mathrm{S}(2 p)$ do not vary sig- nificantly, thus indicating the formation of stable $\mathrm{CuS}$ nanoparticles (Fig. 6). In both samples 2 and 3, the main peak at 74.6-74.9 eV indicate the presence of $\mathrm{AlCl}_{3}$ along with the $\mathrm{Si}$ in polymeric silica form (B.E. $102.6 \mathrm{eV}$ ).

The relative atomic concentrations of key elements in the $\mathrm{CuS}$ nanoparticles matrix for samples 1, 2, and 3 are listed in Table II(a) and the corresponding survey spectra are shown in Fig. 7. Sample 3 shows the highest amount of $\mathrm{Cu}$ and $\mathrm{S}$ concentration as compared to 1 and 2 . These ratios suggest that $\mathrm{Cu}$ is in excess and $\mathrm{S}$ is relatively deficient in the $\mathrm{CuS}$ heated films (suggesting $\mathrm{Cu}^{+1}$ formation). The migrating copper ions fill the copper deficient sites in the top most layer of copper sulfide and improve its stoichiometry. ${ }^{19} \mathrm{Au}-$ ger analysis (outer most layer) of the heated $\mathrm{CuS}$ sample indicates $\mathrm{Cu} / \mathrm{S}$ to be 0.9 . The $\mathrm{Cl}$ concentration decreases and the $\mathrm{Cu} / \mathrm{Cl}$ ratio increases from samples 1 to 3 , indicating the transformation of $\mathrm{CuCl}_{2}$ to $\mathrm{CuS}$. The reduction of $\mathrm{Si}$ and $\mathrm{O}$ concentration (from samples 1 to 3 ) in the film suggests the burning and removal of the sol-gel from the film matrix during heat treatment.

The valence band spectra [Figs. 8(b) and 8(c)] for samples 2 and 3 are quite different from sample 1 [Fig. 8(a)]. A broad feature $(4-9 \mathrm{eV})$ in the valence band spectrum in sample 1 [Fig. 8(c)] indicates the amalgamation of silica (in silica gel) and aluminum (in $\mathrm{AlCl}_{3}$ ), but no prominent aluminosilicate network was found in comparison with the studies of various valence band spectra of aluminum silicates. ${ }^{18,20}$ The band gap in sample 3 reduces to 0.9 from $3 \mathrm{eV}$ (in sample 1) with an increase in the $\mathrm{Cu}(3 d)(2.1 \mathrm{eV}$ B.E.) density of states and a similar rise is noted in the $\mathrm{Cu}$ concentration in the survey spectrum [Fig. 7(c)]. The reduction in the band gap might lead to an increase in the conductivity of the film, an important parameter to be utilized in possible solar cell applications.

It appears that the change in the binding energy may be 

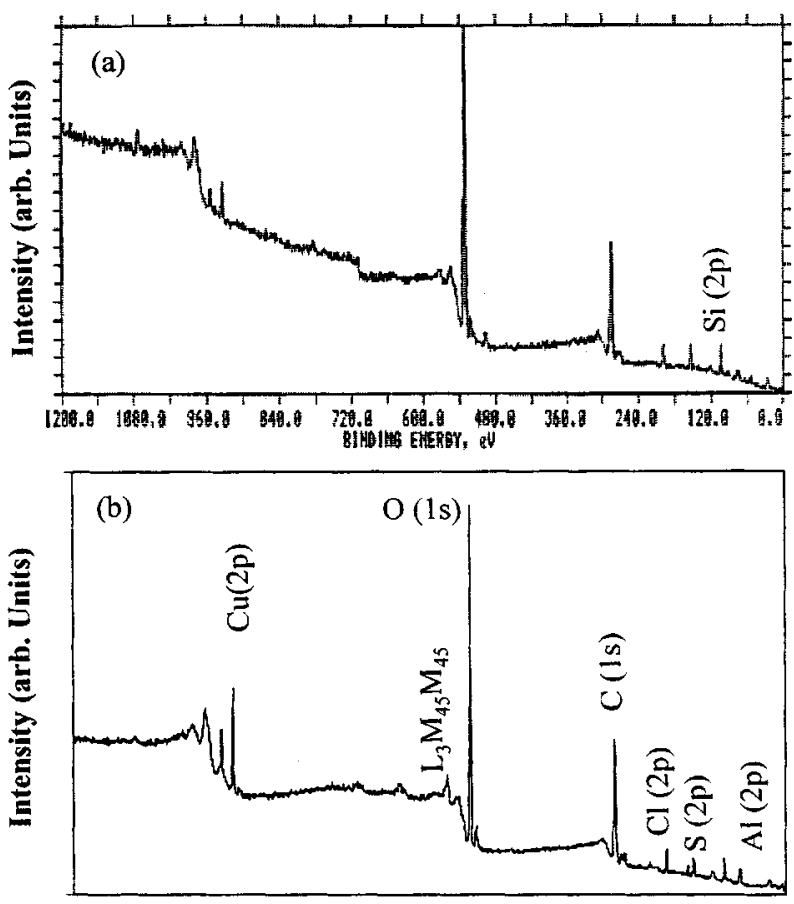

$12001065 \quad 930 \quad 795 \quad 660 \quad 525 \quad 390 \quad 255 \quad 120 \quad 0$

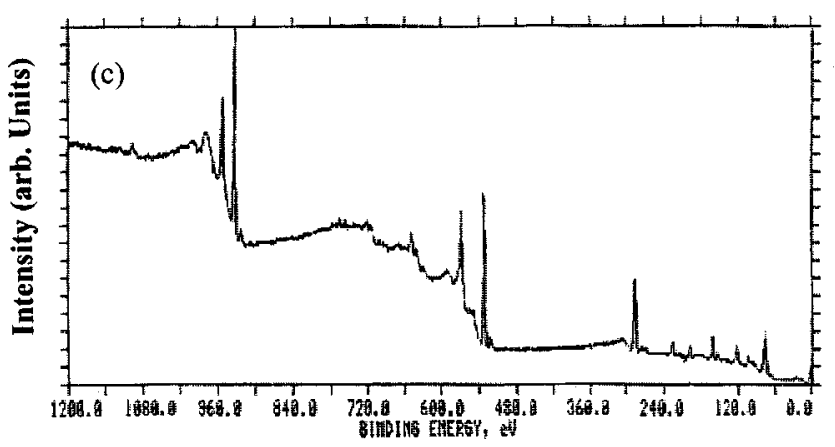

FIG. 7. XPS $0-1200$ survey spectra for $\mathrm{CuCl}_{2} \cdot 2 \mathrm{H}_{2} \mathrm{O} / \mathrm{HPC} /$ silica sol/ $/ \mathrm{AlCl}_{3}$ (a) no $\mathrm{H}_{2} \mathrm{~S}$, no heat, (b) $\mathrm{H}_{2} \mathrm{~S}$, no heat, (c) $\mathrm{H}_{2} \mathrm{~S}$, heat.

sometimes too small to detect the exact change in the $\mathrm{Cu}$ valence state to determine the differences between $\mathrm{CuS}$ and $\mathrm{Cu}_{2} \mathrm{~S}$. Bhide et al. ${ }^{14}$ have shown that metal Auger line intensity ratios such as $\mathrm{Cu}\left(L_{23} M_{45} M_{45}\right)$ to $\mathrm{Cu}\left(L_{23} M_{23} M_{23}\right)$ are quite sensitive to the occupancy of valence band states of the metal in their oxides and sulfides. The introduction of a parameter (Auger parameter), defined by the differences between the two line energies (Auger and photoelectron lines) from the same element in the same sample, is attractive because static charge correction is unnecessary. Hence work functions corrections are unnecessary and vacuum level data can be compared to Fermi level data directly. Thus, the concept of the Auger parameter ${ }^{21}$ is useful to determine and confirm the exact chemical state of $\mathrm{Cu}$ in the copper sulfide particles in support to the core-level XPS binding energy. This parameter is characteristic of chemical and physical states and is easily measurable to an accuracy of $\pm 0.1 \mathrm{eV}$. When the chemical shift in the Auger line is greatly different from that of the photoelectron line, the range in the Auger parameter $(\alpha)$, in $\mathrm{eV}$, can be almost as great as the range in
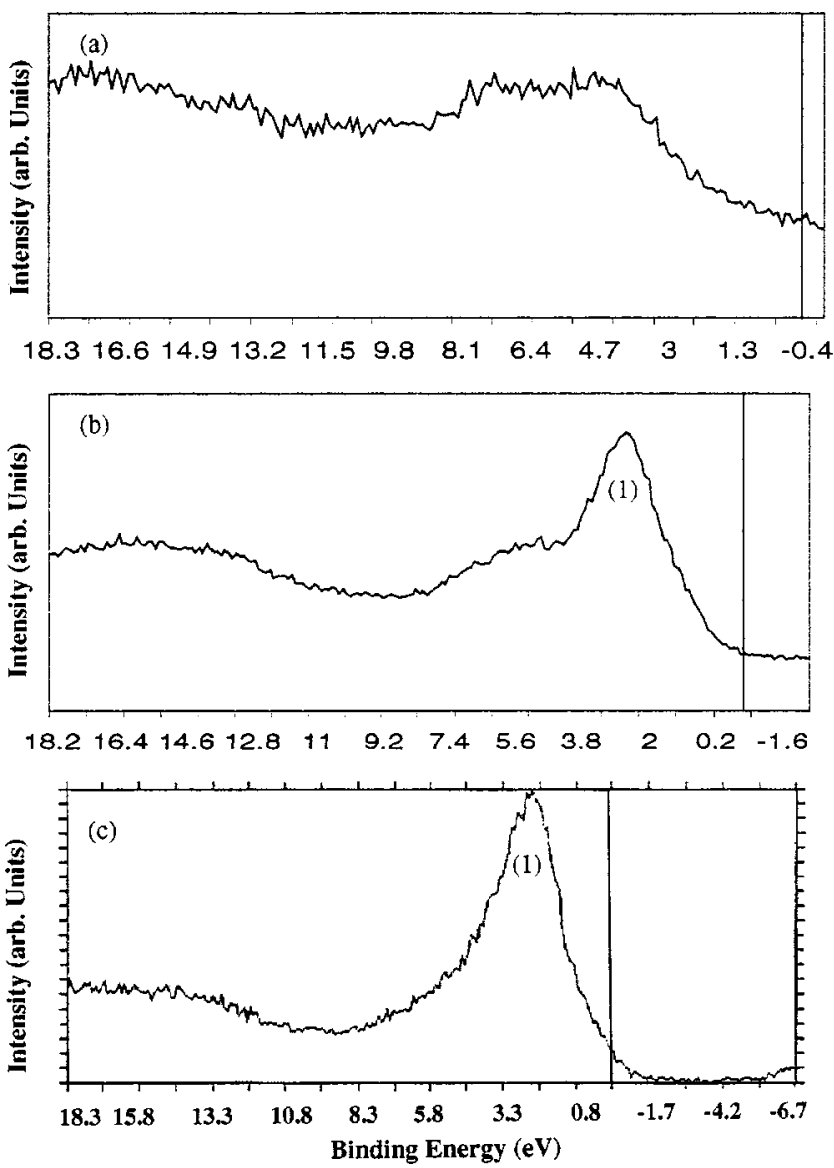

FIG. 8. Valence band XPS spectra for $\mathrm{CuCl}_{2} \cdot 2 \mathrm{H}_{2} \mathrm{O} / \mathrm{HPC} / \mathrm{silica}$ sol/ $/ \mathrm{AlCl}_{3}$ (a) no $\mathrm{H}_{2} \mathrm{~S}$, no heat, (b) $\mathrm{H}_{2} \mathrm{~S}$, no heat, (c) $\mathrm{H}_{2} \mathrm{~S}$, heat. (1) $\mathrm{Cu}(3 d$ ).

the Auger line energy. Table II(b) lists the Auger parameters of the selected $\mathrm{Cu}$ compounds of interest. The calculated $\mathrm{Cu}$ Auger parameter in sample 3 indicates the presence of $\mathrm{Cu}^{+2}$ in $\mathrm{CuS}$, a $1.3 \mathrm{eV}$ shift from that of $\mathrm{Cu}_{2} \mathrm{~S},{ }^{21}$ whereas the core-level binding energy difference is only $0.7 \mathrm{eV}$. Thus, by monitoring the surface chemistry of $\mathrm{Cu}$ and $\mathrm{S}$ in nanoparticles, one can be reasonably assured of the formation of $\mathrm{CuS}$ films via metal precursors through the gas diffusion method.

\section{CONCLUSIONS}

$\mathrm{CuS}$ nanoparticles are successfully fabricated from metal precursors through reaction with $\mathrm{H}_{2} \mathrm{~S}$ gas by the sol-gel process. A hydroxypropyl cellulose derivative is responsible for the production of a uniform particle distribution, while the addition of $\mathrm{AlCl}_{3}$ increases the $\mathrm{Cu}$ solubility limit in the gel matrix. TEM studies of the film show $2-5 \mathrm{~nm}$ spherical sized particles in the matrix. XPS studies of the sulfide particles indicate the formation of $\mathrm{CuS}\left(\mathrm{Cu}^{+2}\right)$. The relative $\mathrm{Cu}$ concentration increases with a shift in the valence band leading edge towards the Fermi line indicating the migration of $\mathrm{Cu}^{+2}$ ions (increase in $\mathrm{Cu} 3 d$ density of states) to the surface during heating, after $\mathrm{H}_{2} \mathrm{~S}$ exposure, thus improving the stoichiometry of the film. The use of the Auger parameter is suc- 
cessfully applied to confirm the presence of divalent $\mathrm{Cu}^{+2}$ and formation of $\mathrm{CuS}$ nanoparticles and not $\mathrm{Cu}_{2} \mathrm{~S}$ in the $\mathrm{H}_{2} \mathrm{~S}$ exposed heated film.

\section{ACKNOWLEDGMENTS}

The authors acknowledge the help of Ms. C. Urbanic and Professor M. Hampton of the Chemistry Department and the use of the UCF-CIRENT Materials Characterization Facility. The authors would also like to thank Dr. Chris Nelson for his assistance in TEM at the National Center for Electron Microscopy, Lawrence Berkeley National Laboratory, University of California, Berkeley.

Presented at the 45th International Symposium of the American Vacuum Society, Baltimore, MD, 2-6 November 1998.

${ }^{1}$ S. K. Khanna, in Handbook of Nanophase Materials, edited by A. N. Goldstein (Marcel Dekker, New York, 1997), p. 1.

${ }^{2}$ T. Lopez, R. Gomez, J. L. Boldu, E. Munoz, L. Bokhimi, and O. Novaro, in Materials-Fabrication and Patterning at the Nanoscale, edited by F. Cerrina and C. Marrian (Materials Research Society, San Francisco, 1996), p. 81

${ }^{3}$ C. J. Brinker and G. W. Scherrer, Sol-Gel Science, The Physics and Chemistry of Sol-Gel Processing (Academic, New York, 1990).

${ }^{4}$ D. C. Bradley, Chem. Rev. 89, 1317 (1989).
${ }^{5}$ D. J. Twait, W. J. Lackey, A. W. Smith, W. Y. Lee, and J. A. Hanigofsky, J. Am. Ceram. Soc. 73, 1510 (1990).

${ }^{6}$ A. McCormick, Sol-Gel Processing and Applications, edited by Y. A. Attia (Plenum, New York, 1994), p. 3.

${ }^{7}$ M. L. Steigerwald and L. E. Brus, Acc. Chem. Res. 29, 183 (1990).

${ }^{8}$ Y. Wang and N. J. Herron, J. Phys. Chem. 95, 525 (1991).

${ }^{9}$ H Uchida, C. J. Curtis, P. V. Kamat, K. M. Jones, M. Kim, and A. Nozik, J. Phys. Chem. 96, 1156 (1992).

${ }^{10}$ T. L. Barr and S. Seal, J. Vac. Sci. Technol. A 13, 1239 (1995).

${ }^{11}$ P. M. A. Sherwood, in Practical Surface Analysis by Auger and Photoelectron Spectroscopy, edited by D. Briggs and M. P. Seah (Wiley, London, 1983), p. 445.

${ }^{12}$ P. M. A Sherwood, in Data Analysis in XPS and AES in Practical Electron Spectroscopy, edited by D. Briggs and M. P. Seah (Wiley, New York, 1990), Appendix 3, p. 555.

${ }^{13}$ M. Toki, J. Sol-Gel Sci. Technol. 2, 97 (1994).

${ }^{14}$ V. G. Bhide, S. Salkalachen, A. C. Rastogi, C. N. R. Rao, and M. S. Hedge, J. Phys. D 14, 1647 (1981)

${ }^{15}$ T. A. Witten and L. M. Sander, Phys. Rev. Lett. 47, 1400 (1981).

${ }^{16} \mathrm{P}$. Meakin in On Growth and Form, edited by H. E. Stanley and N. Ostrowsky (Martinus-Nijhoff, Boston, 1986), pp. 111-139.

${ }^{17}$ D. A. Porter and K. E. Easterling, Phase Transformation in Metals and Alloys (Chapman and Hall, London, 1992).

${ }^{18}$ S. Seal, S. Krezoski, T. L. Barr, D. H. Petering, J. Klinowski, and P. Evans, R. Phys. Soc. London, Sect. B 263, 943 (1996).

${ }^{19}$ L. C. Burton and H. M. Windawi, J. Appl. Phys. 47, 4621 (1976).

${ }^{20}$ T. L. Barr, Modern ESCA (Chemical Rubber, Boca Raton, 1994).

${ }^{21}$ C. D. Wagner, Discuss. Faraday Soc. 60, 291 (1975). 